U. S. DEPARTMENT OF AGRICULTURE, BUREAU OF ANIMAL INDUSTRY.-CIRCULAR 183.

A. D. melvin, Chief of Bureau.

\title{
DIRECTIONS FOR CONSTRUCTING A VAT AND DIPPING CATTLE TO DESTROY TICKS.
}

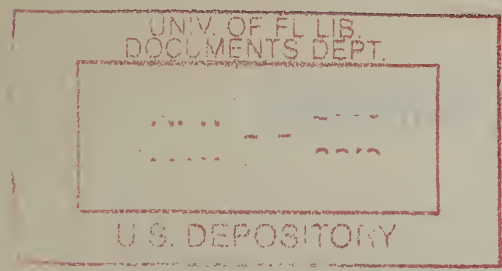

BY

H. W. GRAYBILL, D. V. M., Assistant Zoologist, Zoological Division, AND

W. P. ELLENBERGER, D. V. S., Veterinary Inspector, Inspection Division.

WASHINGTON:

GOVERNMENT PRINTING OFFICE.

1911. 


\section{THE BUREAU OF ANIMAL INDUSTRY.}

Chief: A. D. MelviN.

Assistant Chief: A. M. FARRINGTON.

Chief llerk: Charles C. CARroli.

Animal Husbandry Division: George M. Romrer., chief.

Biochemic Division: M. Dorset, chief.

Dairy Division: B. H. RAWL, chief.

Inspection Division: RICE P. StedDon, chief; MorRIS WOODEN, R. A. RAMSAY, and AlberT E. BeHNKe, associate chiefs.

Pathological Division: JoHN R. MoHLER, chief.

Quarantine Division: Richard W. Hickman, chief.

Zoological Division: B. H. Ransour, chief.

Experiment Station: E. C. SCHROEDER, superintendent.

Editor: James M. Pickens. 


\section{LETTER OF TRANSMITTAL.}

United States Department of Agriculture, Bureau of Animal Industry, Washington, D. C., September 18, 1911.

SIR: I have the honor to transmit the accompanying paper entitled "Directions for Constructing a Vat and Dipping Cattle to Destroy Ticks," by Drs. H. W. Graybill and W. P. Ellenberger, of this bureau. This circular not only gives directions for preparing arsenical dips and for dipping cattle, but contains plans and specifications for the construction of a suitable dipping vat. It has been prepared to meet the need for such information in connection with the work being done by the bureau in cooperation with State and local authorities for the eradication of the ticks which spread the contagion of Texas or southern cattle fever. I respectfully recommend. that it be published in the circular series of this bureau.

Respectfully,

Hon. Jànes WiLson,

A. D. Melvin, Chief of Bureau.

Secretary of Agriculture.

$14556^{\circ}$-Cir. 183. 


\section{O N TENTS.}

Page.

Arsenical dips. . . . . . . . . . . . . .

Preparation and use of arsenical dips............................ 5

Precautions in the use of arsenic.............................. 8

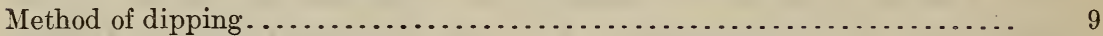

Specifications for the construction of a concrete cattle-dipping vat. . . . . . $\quad 10$

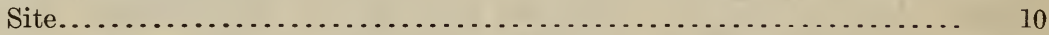

Excavation............................................ 10

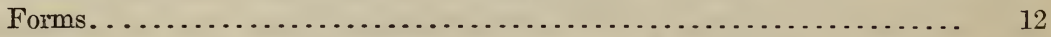

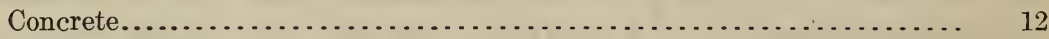

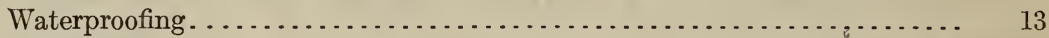

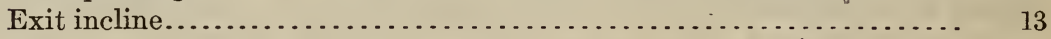

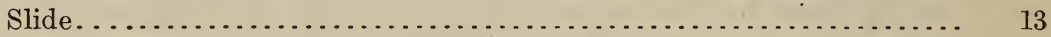

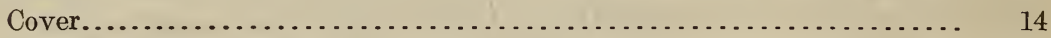

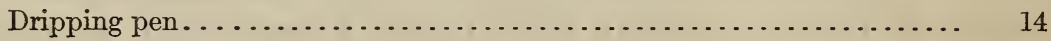

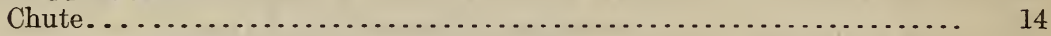

Bill of materials for vat, dripping pen, and chute.................. 14

\section{L L U S T R A T I 0 N.}

FIG. 1. Plans for a concrete dipping vat. 


\section{DIRECTIONS FOR CONSTRUCTING A VAT AND DIPPING CATTLE TO DESTROY TICKS.}

In the course of the work of tick eradication, which the Bureau of Animal Industry has undertaken in cooperation with the States of the quarantined area, there has arisen a demand for a brief publication treating of the preparation and use of arsenical dips and giving plans and specifications for a dipping vat suited to the conditions and requirements on the ordinary farm. ${ }^{1}$ It is with the view of supplying this information that the present circular has been prepared. Those who may desire information on the life history of the tick or further information relating to methods of its eradication are referred to more extensive publications on those subjects. ${ }^{2}$

\section{ARSENICAL DIPS.}

Arsenical dips as agents for destroying cattle ticks have come into much favor during the past few years. This has been due to their efficacy, cheapness, the ease with which they are prepared, and the comparatively slight injury they cause to cattle when properly prepared and used. Homemade dips are the ones most commonly used and are quite satisfactory in every way when ordinary care is used in their preparation. Recently there has been placed on the market a proprietary concentrated arsenical dip which has given good results. This dip is prepared for use by diluting it with cold water in the proportions of 1 to 100 . The only advantage in such a dip is that comparatively little time is required in preparing the bath, but this adrantage is largely counterbalanced by the fact that it is more expensive than a homemade dip.

\section{PREPARATION AND USE OF ARSENICAL DIPS.}

The formula most commonly used in making an arsenical dip is the following:

Sodium carbonate (sal soda) -

Arsenic trioxid (white arsenic)

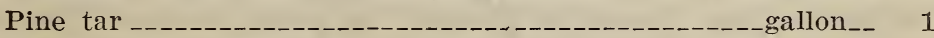

Water sufficient to make 500 gallons.

\footnotetext{
1 In preparing the plans of the vat shown in this circular consideration has been given to the question of cost as well as to practicability of design. The plans for a vat that has been used extensively and witb much success by bureau inspectors in the tick eradication work in Alabama have been followed in part.

2 Farmers' Bulletin 378, Bureau of Animal Industry Bulletin 130, and Bureau of Entomology Bulletin 72, all issued by the United States Department of Agriculture.
} 
If for any reason a stronger dip is desired, 25 pounds of sodium carbonate and 10 pounds of arsenic trioxid may be used in place of the amounts given in the above formula. The stronger dip is required by the regulations of the Bureau of Animal Industry in the dipping of cattle which are to enter interstate commerce from quarantined areas, but for ordinary eradication work when immediate removal of the cattle to tick-free areas is not contemplated it will probably, be best to use the reaker solution, and this is especially true during hot weather and when the animals are to be treated every two weeks.

In preparing the dip a large caldron or galvanized tank is required for heating the water in which to dissolve the chemicals. Thirty or forty gallons of water should be placed in the caldron or tank and brought to a boil. The amount of sodium carbonate indicated in the formula is then added and dissolved by stirring. When this is accomplished, the required amount of arsenic is added and dissolved in a similar manner. The fire is then drawn, and the solution permitted to cool to $140^{\circ} \mathrm{F}$., or this process may be hastened by the addition of cold water. The pine tar is then added slowly in a thin stream and thoroughly mixed with the solution by corstant stirring. This solution is diluted to 500 gallons before using.

If a larger caldron or tank is available for preparing the dip, a greater quantity of solution may be prepared at one time, always, of course, in the same proportion as the above. In this way the time required in preparing the amount of solution necessary to fill a vat is reduced considerably. In case it is necessary to use a smaller container, say of about the capacity of 25 gallons, only half the amount of solution indicated should be prepared at one time, the quantities of ingredients used being half those in the formula. This will, however, require so much time in preparing the amount of solution necessary to fill a vat that when possible it is advisable to provide a larger vessel for dissolving the chemicals.

The caldron or tank and utensils used in preparing the dip should be kept free from grease or oil, as small quantities of these may envelop particles of arsenic and prevent or hinder the solution of the arsenic. It should also be borne in mind that when hard water is used in the preparation of the dip the dissolving of the sodium carbonate (sal soda) in the boiling water results in the formation of a fine white or gray insoluble powder or precipitate of lime salts which may be taken for undissolved arsenic, and thus lead to the belief that all of the arsenic has not gone into solution.

The arsenical solution may be poured into the vat as rapidly as it is prepared until the amount required to fill the vat, when properly diluted, has been made. The most convenient way of diluting the solution is to run the water into the vat through a hose or pipe. 
The capacity of the vat at the depth to which it is necessary to fill it for dipping, if not known, should be calculated, and for future convenience the water line should be plainly marked at some point on the wall of the vat. After the exact amount of solution necessary to furnish diluted dip to fill the vat has been prepared and placed in the rat all that is necessary is to allow water to flow into the vat until the surface of the dip reaches the mark made on the side of the rat. For example, if the capacity of the vat is 2,000 gallons, then four times the amount of solution necessary to make 500 gallons of dip should be prepared, placed in the vat, and the latter filled with water to the 2,000-gallon mark. In case the vat leaks it will be necessary to modify the above procedure by placing the concentrated arsenical solution necessary to fill the rat in barrels and only placing it in the vat when the latter is nearly filled with water, being careful to note, howerer, that there is ample capacity remaining so that when the solution in the barrel is added the dip surface will not be above the mark to which the vat is to be filled.

The capacity of the rat planned in this circular at a depth of 5 feet 3 inches is 1,470 gallons. In order to fill it to that depth with dip it will be necessary to prepare two batches of concentrated dip each containing the ingredients necessary for making 500 gallons of diluted dip and a third batch containing 7 pounds 9 ounces of arsenic and 22 pounds 3 ounces of sodium carbonate in case 8 pounds of arsenic are being used to the 500 gallons, or 9 pounds 7 ounces of arsenic and 22 pounds 8 ounces of sodium carbonate in case 10 pounds of arsenic are being used to the 500 gallons.

When for any reason it is not convenient to follow the above method of diluting the dip, a stock solution may be prepared in which the quantity of ingredients for 500 gallons of diluted dip are dissolved in 50 gallons of water. Nine parts of water to 1 part of this stock solution will then give the proper dilution. The stock solution is found rery convenient for replenishing the dip in a vat when it has become too low for dipping. A stock solution should not be made in more concentrated form than that given ( 50 gallons of stock for 500 gallons of dip), as the pine tar does not remain properly mixed when the solution is too concentrated.

The arsenical dip may be left in the vat and used repeatedly, replenishing it with the proper quantities of water and stock solution when necessary. When, however, the dip becomes filthy through the addition of manure and dirt carried in by the cattle, the vat should be emptied, cleaned, and filled with fresh fluid. The frequency with which this should be done must be left to the owner, as the condition of the dip at any period after it has been made depends on a variety of conditions, such as the number of cattle dipped, the frequency of the dippings, etc. Even though the dip may not become very filthy, 
itss efficacy decreases somewhat on standing, owing to gradual oxidation of the arsenic. It is therefore adrisable to recharge the rat if the dip is more than a month or six meeks old irrespectire of its condition as to cleanliness.

At the conclusion of each dipping it is well to mark the position of the surface of the dip on the side of the vat in order to determine at the next dipping whether there has been a change in the level of the dip. If the surface of the dip has fallen and it is known that the vat does not leak, there has been a loss of water by evaporation and consequently an increase in the strength of the dip. In order to bring the dip down to its former strength water should be run into the vat until the dip surface reaches the mark made at the last dipping. If the fall has been due to the rat leaking, the strength of the dip has not been altered and consequently water alone should not be added. If the dip surface has been raised by rain the amount of water added in this way should be determined by calculation, and for every nine gallons of water one gallon of the stock solution previously mentioned should be used.

When not in use the vat should be tightly corered with a waterproof cover to prevent evaporation on the one hand and further dilution by rain on the other hand. Securely covering the vat when not in use also lessens the risk of accidental poisoning of stock and human beings.

\section{PRECAUTIONS IN THE USE OF ARSENIC.}

On account of the fact that arsenic is a dangerous poison, great care must be observed in making and using the arsenical dip. From the time the arsenic is procured from the druggist until the last particle of unused residue is properly disposed of, the most scrupulous care should be taken in handling it. Guessing at weights or measures or carelessness in any particular is liable to result in great damage, and not only may valuable live stock be destroyed, but human beings may lose their lives as well.

Persons using the dip should bear in mind the possibility of absorbing arsenic through cuts, scratches, or abrasions of the skin and also by inhalation of vapors from the boiler in which the dip is prepared. It should be remembered that the absorption of even very small quantities of arsenic, if repeated from day to day, is liable ultimately to result in arsenical poisoning.

Cattle should always be watered a short time before they are dipped. After they emerge from the vat they should be kept on a draining floor until the dip ceases to run from their bodies; then they should be placed in a yard free of vegetation until they are entirely dry. If cattle are allowed to drain in places where pools of dip collect, from which they may drink, or are turned at once on the pasture, where the dip will run from their bodies on the grass and other vegetation, serious losses are liable 
to result. Crowding the animals before they are dry should also be avoided, and they should not be driven any considerable distance within a week after dipping, especially in hot weather. If many repeated treatments are given the cattle should not be treated oftener than every two weeks.

In addition to properly protecting vats containing arsenical dip when not in use, another precaution must be observed when vats are to be emptied for cleaning. The dip should not be poured or allowed to flow on land and vegetation to which cattle or other animals have access. The best plan is to run the dip into a pit properly protected by fences, and the dip should not be deposited where it may be carried by seepage into wells or springs which supply water used on the farm.

The above precautions are given to inform persons not familiar with arsenic of its poisonous nature and the care that should be observed in its use, and to stimulate a proper care in those who know its poisonous nature and yet might be careless or who may not know all the precautions that should be observed. Unfortunately, however, the giving and emphasizing of such precautions have had the effect of arousing unwarranted fear of arsenic on the part of some stockmen and farmers, and have caused them, for a time at least, to refuse to undertake its use in treating cattle for ticks. For the benefit of those who may unduly fear arsenic because of what has been said, it should be stated that when reasonable care is observed in following the precautions given there is little danger of losses occurring. The-arsenical dip has been extensively used during the past five years in tick-eradication work in the tick-infested area, and considering the number of cattle that have been dipped the losses have been very small. Some of these losses have been definitely traced to carelessness, and there is little doubt that if it had been possible to inrestigate all losses the majority of them would have been found to be due to this cause.

\section{METHOD OF DIPPING.}

The procedure to be followed in dipping animals on a farm depends on the end that is sought in undertaking the treatment. If it is simply desired to reduce and keep down the infestation of ticks on a farm, it will only be necessary for the owner to keep his animals under observation and dip them when, according to his judgment, treatment is necessary to keep the ticks under control. Such a procedure may well be followed where the regular tick eradication is not under way; that is, in instances in which it is not yet practicable or expedient to rid farms completely of ticks.

If, hotrever, it is desired to rid the farm completely of ticks-and this should be the purpose in every case in which it is practicable and expedient-it will be necessary to dip all cattle, and also any horses, 
mules, or asșes that may harbor the cattle tick, at regular intervals until all ticks have disappeared from the farm. The purpose of such dipping is to prevent as nearly as possible any engorged females dropping to the pasture and there laying eggs which in time may develop into young ticks. In order to do this it is necessary to dip at intervals short enough so that no tick after getting on the cattle will have time to mature and drop off before the next dipping. An interval between dippings of two weeks is considered most satisfactory. This interval, however, may be increased somewhat if necessary, but it should never be greater than three weeks.

In freeing a farm of ticks the dipping should not be discontinued until it has been determined with certainty that the cattle and premises are free of ticks. It should be borne in mind that it is almost impossible to determine by a few inspections, even if carried out with great care, that animals are free from ticks. If the treatment is discontinued and a few unobserved ticks are still on the animals, these, on maturing and dropping, are likely to give rise to a new brood of young ticks. Moreover, eren if the cattle are actually free from ticks, the fact should not be lost sight of that there may still be engorged females, eggs, and seed ticks on the premises. This is most likely to be the case during the colder part of the year when the derelopment of the tick on the ground progresses slowly and also when any seed ticks that may be present are likely to be slow in reaching the cattle because of inactivity resulting from the low temperature.

\section{SPECIFICATIONS FOR THE CONSTRUCTION OF A CONCRETE CATTLE-DIPPING VAT.}

SITE.

The site selected for the location of the rat should be dry and of sufficient size to admit of the construction of the chute, the dripping pen, and at least two additional pens-one for holding the cattle prior to dipping and the other for retaining them after dipping until sufficiently dried.

\section{EXCAYATION.}

The excavation should be made 1 foot wider and 1 foot longer than the inside dimensions of the vat and should conform to its shape. The inside dimensions of the vat are shown on the drawings (fig. 1) and are as follows: Length at top of rat, 26 feet; bottom, 12 feet. Width at top, 3 feet; at bottom, $1 \frac{1}{2}$ feet. Depth, $6 \frac{1}{2}$ feet.

The sides and bottom of the excavation should be firm and solid, as they are to serve for the outside forms in casting the concrete. If it is necessary to do any filling in order to conform to the shape of the rat, the filling should be puddled and thoroughly rammed until solid, because the stability of the concrete depends on the foundation. 


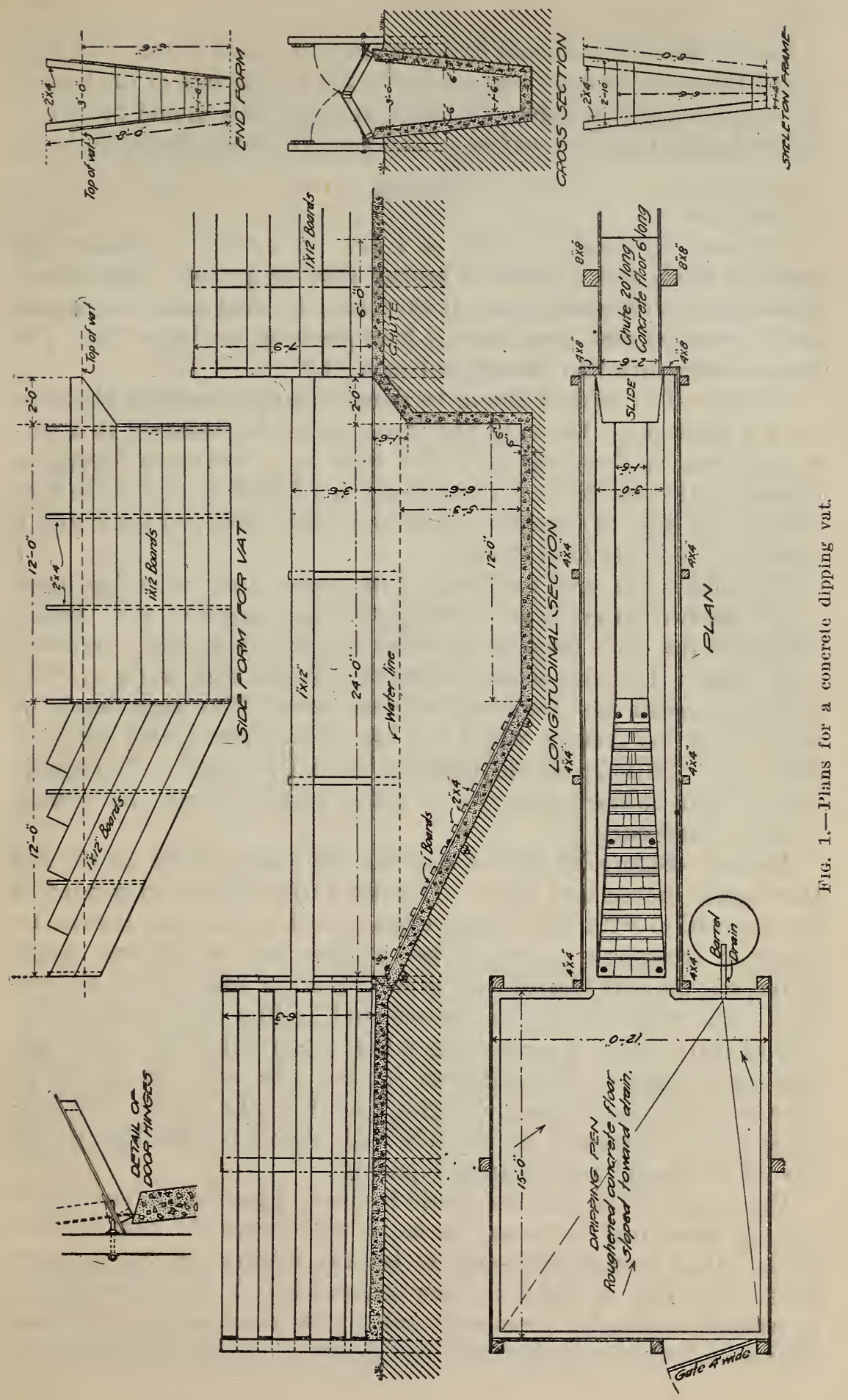




\section{FORMS.}

The wooden forms should be constructed of 1 -inch boards and 2 by 4 inch braces, the boards being nailed to the outside face of the braces, as shown in the drawings. The sides and end walls should be built 8 inches higher than the surface of the ground, which should be level.

\section{CONCRETE.}

The concrete should be made of 1 part of cement, by measure, $2 \frac{1}{2}$ parts of sand, and 5 parts of broken rock or gravel. The cement should be of a standard brand of Portland, the sand clean and coarse, and the broken rock from about $\frac{1}{4}$-inch pieces to not larger than will pass in every direction through a 1-inch ring.

Mixing.-The mixing should be done on a tight wooden platform or in a tight box. The sand and stone should be measured in a bottomless box, $2 \frac{1}{2}$ feet long by 2 feet wide by 1 foot deep, having a capacity of 5 cubic feet. A convenient size of batch to mix is one consisting of 2 bags of cement, 1 measure ( 5 cubic feet) of sand, and 2 measures (10 cubic feet) of stone.

The sand is measured out first and the cement emptied on top, after which the two materials are thoroughly mixed together, dry. In the meantime the stone may be measured out and thoroughly drenched with water. The cement-sand mixture is mixed with water and the resulting mortar then combined with the stone. The stone should be shoveled on the mortar, which has been previously spread out in a thin layer. Mixing should continue until the stone is thoroughly coated with mortar, more water being added during the mixing process if necessary.

Laying.-Before laying the concrete the molds should be set and thoroughly braced into place. The side forms may be suspended in the excavation with their lower edges 6 inches from the bottom by means of crosspieces nailed to the uprights and of sufficient length to rest on supports located several feet from the edges of the excaration. The concrete for the bottom and incline is deposited first, this mixture being of a consistency that water will flush to the surface on ramming. The mixtures for the sides and end should be very wet and should be thoroughly puddled into place. The consistency of the concrete for the side walls should be such that it will run off the shovel unless handled quickly.

The laying of the concrete should be done, if possible, in one opera- . tion, in order that there may be no joints between the new and old work. If it becomes necessary to lay the concrete on two or more days the surface on which the new concrete is to be deposited should be washed thoroughly clean and coated with grout of pure Portland cement and water mixed to the consistency of cream. The new con- 
crete should be placed before the grout has set. Extreme care should be taken to prevent dirt from falling in on top of the deposited concrete.

The forms should not be removed until the concrete is set, which in moderate weather will have taken place in about 24 hours. In damp, cold weather at least 48 hours should be allowed before removing the forms. It will be advisable, especially in water-soaked ground, to allow the forms to remain in place for one week before removal.

Finishing coat.-Before applying the surface coat dampen the walls and floor thoroughly. Cover the entire exposed surface of the floor and walls with a coating one-half inch thick of cement mortar composed of Portland cement 1 part, sand 2 parts. Coating to be floated and troweled to a smooth finish.

\section{WATERPROOFING.}

If the earth around the vat is thoroughly drained the vat may be waterproofed by painting the surface coat, but painting the surface will not give satisfactory results if there is ground water to seep in. The paint may be good hot pine tar, or gas-house tar cut with naphtha or gasoline and applied with a brush, or after the mortar coat has hardened the inside of the vat may be painted with an oil-cement paint made as follows: ${ }^{1}$ Mix enough water with Portland cement to make a fairly stiff paste; add to this 5 per cent of heavy petroleum residuum oil based on the weight of the cement, and mix thoroughly until the oil entirely disappears, then add more water and stir until a paint of the consistency of cream is formed. This paint should be applied with a brush and should be well rubbed into the surface. Should the mortar coat be omitted the paint coat should be applied directly to the surface of the concrete.

\section{EXIT INCLINE.}

As the exit incline is to have a false wooden floor, it will be necessary to embed iron bolts in the concrete, to which the wooden floor may be fastened. Before the concrete incline is laid embed in the dirt three pieces of 2 by 4 inch scantling, placed at the top, center, and bottom of the incline. The bolts should extend through these pieces and should be placed with the head next to the dirt. The bolts should be long enough to extend through the concrete and the inch boards of the floor, so that the wooden floor may be securely fastened.

\section{SLIDE.}

Cover the slide with a sheet of boiler iron properly fastened to the cement.

1 These directions for the oil-cement paint are furnished by the Office of Public Roads of the United States Department of Agriculture. 
COVER.

The cover of the vat consists of two leaves hinged on posts set 3 feet in the ground along each side of the rat. The leaves are 2 feet 6 inches wide, and when open rest against the upper part of the posts to which they are hinged and serve as splash boards. The details of the hinge ${ }^{1}$ used and the method of setting it are shown in the drawings. When the leares are open their lower edges are just above the top of the side walls, which are given a slope inward for the purpose of conducting the dip running from the splash boards back into the vat. 'Removable doors should be constructed to close the triangular openings left at the ends of the rat when the cover is closed. The hinges may be made by a blacksmith.

\section{DRIPPING PEN.}

Construct a dripping pen about 12 by 15 feet at the head of the exit incline. The floor should be of concrete prepared as previously described for the rat and laid in a similar manner. The floor should be pitched toward a corner of the pen, where a pipe should be laid in the floor to carry the drippings into a barrel sunk in the ground. The drippings thus caught may be returned to the rat after settling. The floor should be roughened to prevent the cattle from slipping.

\section{CHCTE.}

The chute leading to the vat should be built 30 inches wide and 20 feet long; and the receiving and retaining pens should be of a size to take care of the animals to be dipped.

\section{BILL OF MATERIALS FOR VAT, DRIPPING PEN, AND CHUTE.}

\section{LUMBER IOR FORMS.}

8 pieces 1 by 12 inches by 14 feet long.

13 pieces 1 by 12 inches by 12 feet long.

2 pieces 1 by 12 inches by 9 feet long.

2 pieces 1 by 12 inches by 6 feet long.

2 pieces 1 by 12 inches by 4 feet long.

8 pieces 2 by 4 inches by 8 feet long.

2 pieces 2 by 4 inches by 7 feet long.

2 pieces 2 by 4 inches by 6 feet long.

2 pieces 2 by 4 inches by 4 feet long.

2 pieces 2 by 4 inches by 2 feet long.

7 pieces 1 by 6 inches by 12 feet long for crosspieces for inside of forms.

\section{LCMBER FOR DRIPPING PEN.}

7 pieces 6 by 6 inches by 10 feet long for posts.

10 pieces 1 by 8 inches by 16 feet long for side rails of pen.

5 pieces 1 by 8 inches by 12 feet long for side rails of pen.

5 pieces 1 by 8 inches by 8 feet long for side rails of pen.

1 This hinge and the method of sefting it for the corer of a dipping rat hare been copied from an article by William Taylor Heslop in the Agricultural Journal of the Union of South Africa, Pretoria; vol. 1, No. 1, 1911, pp. 38-43. 
The covers can be made from the lumber used in making the forms, and the lumber for the exit incline can be gotten in the same way.

The 4 by 4 inch posts to which the cover is hinged may be made from 2 by 4 stuff by spiking together.

End form to be made solid.

HARDWARE AND IRONWORK.

6 bolts, $\frac{1}{2}$ by 10 inches, with nuts and washers, for false floor of incline.

1 sheet of $\frac{1}{4}$-inch boiler iron cut to shape of slicle; plate bored and countersunk for four screws.

4 pairs hinges for covers.

3 heary $T$ hinges and screws for gate of dripping pen.

1 heary iron bolt to fasten gate.

CONCRETE.

VAT.

Cement, $10 \frac{1}{2}$ barrels ( 42 bags).

Sand, $3 \frac{3}{4}$ cubic yards.

Stone, $6 \frac{1}{4}$ cubic yards.

DRIPPING PEN AND CHUTE.

Cement, $5 \frac{1}{2}$ barrels (22 bags).

Sand, $1 \frac{3}{4}$ cubic yards.

Stone, $3 \frac{1}{2}$ cubic yards.

A 26-foot vat has been used extensively for eradication purposes with satisfactory results. However, if it is desired to lengthen the body of the vat on account of large numbers of cattle to be treated, or to make it conform to the bureau's requirements for the treatment of cattle for movement as noninfectious, there should be added to the amount of concrete material for each lineal or running foot, cement, 0.37 barrel; sand, 0.12 yard; stone, 0.24 yard.

$\mathrm{By}$ some a dripping chute is regarded more satisfactory than a - dripping pen. One of the advantages that it has is that the cattle are held in line in the order in which they have been dipped, thus making it possible to remove one or more of them at a time as soon as they have drained sufficiently, in order to make room for others. In using the dripping pen this is not practicable and it is necessary to wait until the last animal dipped has drained sufficiently and then remove them all together.

In case it is desired to construct a dripping chute it should be located at the head of the exit incline in line with the vat. It should be about 36 inches wide. The length will depend on the number of cattle it is desired to accommodate at one time, it being necessary to allow 4 to 5 feet for each. A length of from 20 to 40 feet is considered a convenient size for small herds. The floor should be made of concrete and sloped toward the vat. The dip should not be permitted to run directly into the vat, but should be collected in a barrel to settle, as shown in the case of the dripping pen. The floor at the sides should be raised about 2 inches in the form of a curb to keep the dip from running off. 
UNIVERSITY OF FLORIDA 